\title{
AN ORTHO-TOLIDINE METHOD FOR THE DETECTION OF OCCULT BLOOD IN FAECES
}

\author{
BY \\ J. KOHN AND T. O'KELLY \\ From Queen Mary's Hospital, Roehampton, London
}

(RECEIVED FOR PUBLICATION DECEMBER 22, 1954)

Benzidine is still the most commonly used reagent for occult blood tests in faeces. About three years ago, however, the manufacture of Anala R benzidine in this country was discontinued as it was shown that benzidine has very marked carcinogenic properties, particularly in some of the stages of purification to AnalaR specification. This did not appear to be widely recognized probably because most laboratories still had stocks of the Anala R benzidine. We drew attention to this state of affairs two years ago (Kohn and O'Kelly, 1952). Since then it has been found that the benzidine available is not sufficiently reliable for occult blood testing even when various methods of purification were tried. This affects, of course, any benzidine method whatever the technique.

A review of other reagents which could replace benzidine showed that ortho-tolidine had been used both for urine and for faecal occult blood tests (Zwarenstein, 1949 ; Hawk, Oser, and Summerson, 1947 ; Caplan and Discombe, 1951). As far back as 1912 and 1913 Ruttan and Hardisty introduced an ortho-tolidine method for demonstrating occult blood in faeces and urine and regarded it as being superior to the benzidine method. Kiefer in 1934 again drew attention to the advantages of the method. O-Tolidine methods, however, did not become very popular, probably partly due to the misconception that they were too sensitive. Trials of various o-tolidine techniques showed that false positive results could be obtained, but on reinvestigating the conditions of the test, the properties of the reagent, and the proportions of its components it appeared that this " over-sensitivity" was due either to wrong proportions of the reagents employed or to the practice of filter paper methods, which tend to produce false results with any reagent. It was then found that the sensitivity of the ortho-tolidine reagent could be modified at will by varying either the concentrations or the proportions of the reagents taking part in the reaction (Figs. 1 and 2 and Table I).

TABLE I

EFFECT OF VARYING CONCENTRATIONS OF O-TOLIDINE ON OCCULT BLOOD TESTING

\begin{tabular}{|c|c|c|c|c|c|}
\hline \multirow{2}{*}{$\begin{array}{c}\text { Concentration } \\
\text { of Blood } \\
\text { in } 10 \% \\
\text { Faecal Suspension }\end{array}$} & \multicolumn{5}{|c|}{$\begin{array}{l}\text { Dilutions of Stock } 4 \% \text { Ortho-tolidine } \\
\text { in 50\% Glacial Acetic Acid }\end{array}$} \\
\hline & $50 \%$ & $33 \%$ & $20 \%$ & $10 \%$ & $5 \%$ \\
\hline $\begin{array}{l}1: 1,000 \\
1: 2,500 \\
1: 5,000 \\
1: 10,000 \\
1: 20,000 \\
1: 30,000 \\
1: 50,000\end{array}$ & $\begin{array}{c}+++ \\
+++ \\
+++ \\
+++ \\
++ \\
+ \\
+\end{array}$ & $\begin{array}{c}+++ \\
+++ \\
++ \\
++ \\
+ \\
=\end{array}$ & $\begin{array}{c}+++ \\
++ \\
+ \\
+ \\
\pm \\
=\end{array}$ & $\begin{array}{l}++ \\
+ \\
+\end{array}$ & \pm \\
\hline \multicolumn{6}{|c|}{ 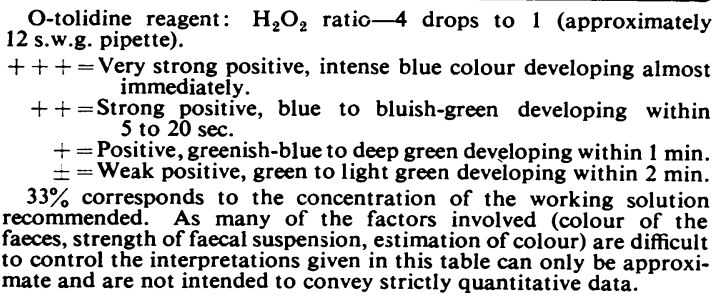 } \\
\hline
\end{tabular}

These investigations and further trials eventually led us to adopt a test-tube technique described below, which has been in routine use in this laboratory for the last three years, during which time over 2,500 examinations have been performed. The method was standardized so that it is slightly less sensitive than the benzidine test, using AnalaR benzidine and the standard textbook technique.

\section{Method}

Reagents.-The following are required :

Stock Solution.-A solution of $4 \%$ ortho-tolidine (AnalaR B.D.H.) in ethanol is made up which is stable for a very long time. At approximately $4^{\circ} \mathrm{C}$. refrigerator temperature it partly precipitates, but this does not affect its efficiency. For practical reasons it was found best to distribute the stock solution in small quantities, e.g., $2 \mathrm{ml}$., into test-tubes, to which 


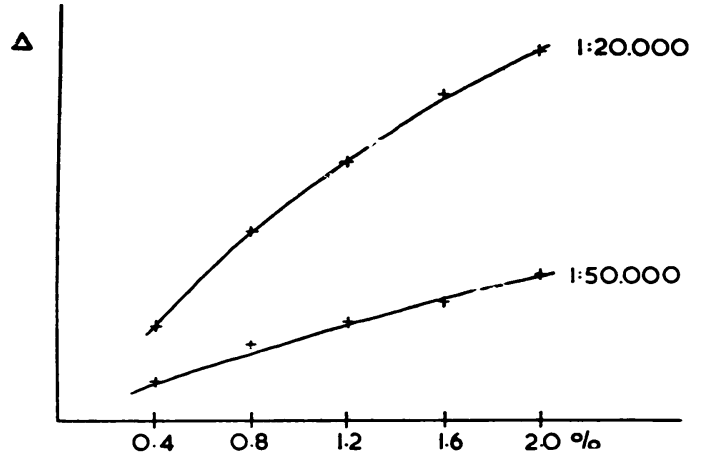

FIG. 1.-Effect of varying the concentration of o-tolidine in the reagent. Concentration plotted against optical density of the colour obtained with two dilutions of blood. One drop of blood-water dilution was added to a mixture of 4 drops of the o-tolidine solution and 1 drop of 20 vol. $\mathrm{H}_{2} \mathrm{O}_{2}$ (12 s.w.g. pipettes were used). After five minutes $4 \mathrm{ml}$. water was added and the optical density $\triangle$ measured in a Spekker absorptiometer.

the diluent is added when required to form the working solution. The precipitate then becomes completely dissolved.

Working Solution.-Equal parts of stock solution, glacial acetic acid and distilled water, which solution, once prepared, is stored at $4^{\circ} \mathrm{C}$. in a refrigerator and is stable for at least a month.

20-Volume Hydrogen Peroxide.-Both the o-tolidine working solution and the hydrogen peroxide are best kept in bottles or tubes fitted with dropping pipettes in the stoppers. This ensures the delivery of constant (if not equal) volumes. T.K. and dropping bottles are not recommended as there may be a large variation in the size of the drops.

Technique.-A portion of faeces about the size of a pea is boiled in about $5 \mathrm{ml}$. of water. Boiling is carried out as, apart from the controversial subject

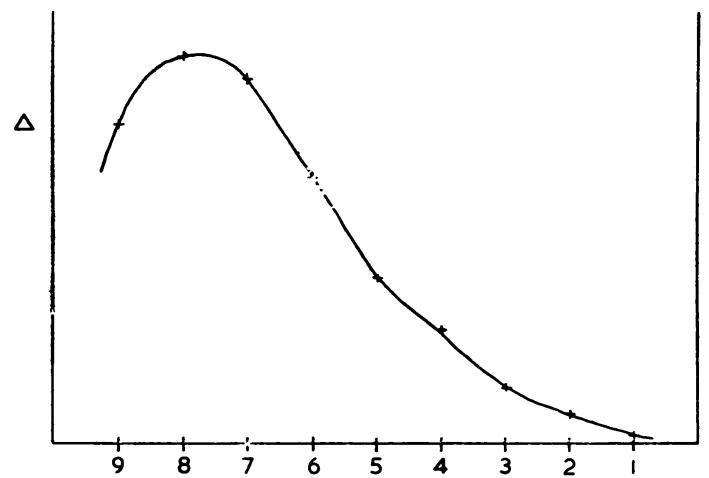

FIG. 2.-Effect of varying the o-tolidine : $\mathrm{H}_{2} \mathrm{O}$, ratio. Ratio plotted against optical density of colour obtained with a 1 in 10 dilution of blood. Figures on the horizontal axis denote number of drops of the o-tolidine working solution. $\mathrm{H}_{2} \mathrm{O}_{2}$ was added to each tube to make up a total of 10 drops (12 s.w.g. pipette). Otherwise procedure as in Fig. 1.

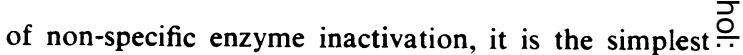
way of obtaining a fairly homogeneous suspension. $\vec{F}$ In our experience the boiling does not appear $\stackrel{0}{\rightarrow}$ materially to affect the final result.

In a clean test-tube are placed 4 drops of the work- $\frac{\bar{\sigma}}{\bar{\sigma}}$ ing solution followed by 1 drop of 20-vol. hydrogen $\frac{\bar{\rho}}{\partial}$ peroxide. This is left standing for one minute to $\stackrel{\mathbb{Q}}{2}$ ensure that there is no contamination of tube or reagent, and 1 drop of the faecal suspension is added. This can be most easily delivered from the $\vec{\circ}$ tip of the glass rod used to mix the faecal suspension, $\overrightarrow{\vec{C}}$ and also has the advantage of giving a fairly constant $\vec{\omega}$ and reproducible volume.

Interpretation.-A positive result is indicated by the appearance of a green or blue colour developing $\omega$ within a minute and lasting from a few minutes to several hours, depending upon the intensity of the reaction. The colour develops more gradually and음 lasts much longer than with benzidine. With increas-二 ing concentration of blood the colour develops more $>$ quickly and changes progressively from green to deep blue. The amount of blood present can thus be $\frac{}{\omega}$ assessed by the colour and by the speed of its development (Table I). We do not think, however, that $\overrightarrow{0}$ any hard and fast interpretation scheme can be of or much real value. The intake of iron salts or $\square$ chlorophyll does not produce false results. Bromides and iodides give a colour change in vitro, but do not appear to interfere with faecal examinations.

Adaptation to Slide-test Technique.-A further $\stackrel{2}{\mathbb{D}}$ attempt was made to adapt the o-tolidine method to the slide-test technique, if for reasons of expediency this is preferred. It was found that the o-tolidine reagents could be employed for this purpose with equally satisfactory results, provided certain precautions are observed. These consist first in using $a-$ water-repellent surface on which the faecal smears? are made. This procedure prevents creeping at the $\frac{\sigma}{3}$ edge of the drop of reagent. (The creeping thin layer. of the reagent dries very rapidly and very often leadso to the appearance of a blue ring which may give the impression of a false positive result.) Secondly, as음 in th: slide technique undiluted faeces is used, $a_{D}$ less sensitive reagent is required. (An average smearo contains at least twice as much faecal material as a drop of faecal suspension.) The decreased sensitivity is achieved by altering the proportions of the reagent. $N$ The following method has been adopted and has given in our hands satisfactory and reliable results.

A cavity porcelain tile is treated with "repelcote silicone (Midland Silicones Ltd.; distributed by Hopkine and Williams), or alternatively smeared thinly with some greasy substance, e.g., vaseline. A smear is then $\stackrel{\mathscr{S}}{+}$ made in one of the cavities with a small amount of $\square$ faeces on a glass rod, orange stick, or the tip of the examining glove. Then a drop of 20-vol. hydrogen peroxide is added to the smear followed by one drop $\overrightarrow{\mathbb{D}}$ of the o-tolidine working solution. A green or bluc $\frac{a}{\sigma}$ colour, depending on the intensity of the reaction. 
developing within one minute indicates a positive result. The interpretation is similar to that of the test-tube technique.

The routine examinations for occult blood in faeces are performed on patients on a three-day controlled meat-free diet. We believe that this precaution is justified, but this paper is solely concerned with a matter of technique. The reagents can, however, be easily adjusted to the sensitivity of the Gregersen test if this is preferred.

\section{Summary}

Attention is drawn to the difficulties in obtaining pure and reliable benzidine for occult blood tests.

A simple method for the detection of occult blood in faeces is described. It has the following advantages :

(1) The working solution is stable and need not be prepared each time a test is performed.
(2) The volumes of the reagents and of the faecal suspension are measured and not guessed approximately, thus introducing a reasonable degree of accuracy.

(3) The method is flexible, as the sensitivity of the test can be modified according to one's particular views or requirements.

(4) AnalaR ortho-tolidine is easily obtainable and the method is economical as only small quantities of the reagents are used.

\section{REFERENCES}

Caplan, H., and Discombe, G. (1951). Brit. med. J., 2, 774. Hawk, P. B., Oser, B. L., and Summerson, W. H. (1947). Practical Physiolozical Chemistry, 12th ed., p. 768. Churchill, London. Kiefer, E. D. (1934). Amer. J. Surg., 25, 530.

Kohn, J., and O'Kelly, T. (1952). Brit. med. J., 2, 1308.

Ruttan, R. F., and Hardisty, R. H. M. (1912). Canad. med. Ass. J., n.s., 2, 995 .

(1913). Biochem. Bull., 2, 225.

Zwarenstein, H. (1949). Journal of Clinical Pathology, 2, 145. 